\title{
Laboratory Evaluation of the Level TROLL 100 Manufactured by In-Situ Inc.- Results of Pressure and Temperature Tests
}

Open-File Report 2013-1173

U.S. Department of the Interior

U.S. Geological Survey 
This page intentionally blank 


\section{Laboratory Evaluation of the Level TROLL 100 Manufactured by In-Situ Inc.-Results of Pressure and Temperature Tests}

By Mark V. Carnley, Janice M. Fulford, and Myron H. Brooks

Open-File Report 2013-1173 


\section{U.S. Department of the Interior \\ SALLY JEWELL, Secretary}

\section{U.S. Geological Survey \\ Suzette M. Kimball, Acting Director}

U.S. Geological Survey, Reston, Virginia: 2013

For more information on the USGS — the Federal source for science about the Earth, its natural and living resources, natural hazards, and the environment, visit http://www.usgs.gov or call 1-888-ASK-USGS.

For an overview of USGS information products, including maps, imagery, and publications, visit http://www.usgs.gov/pubprod

To order this and other USGS information products, visit http://store.usgs.gov

Any use of trade, product, or firm names is for descriptive purposes only and does not imply endorsement by the U.S. Government.

Although this report is in the public domain, permission must be secured from the individual copyright owners to reproduce any copyrighted materials contained within this report.

Suggested citation:

Carnley, M.V., Fulford, J.M., and Brooks, M.H., 2013, Laboratory evaluation of the Level TROLL 100 manufactured by In-Situ Inc.--Results of pressure and temperature tests: U.S. Geological Survey Open-File Report 2013-1173, 12 p., http://pubs.usgs.gov/ofr/2013/1173/. 


\section{Contents}

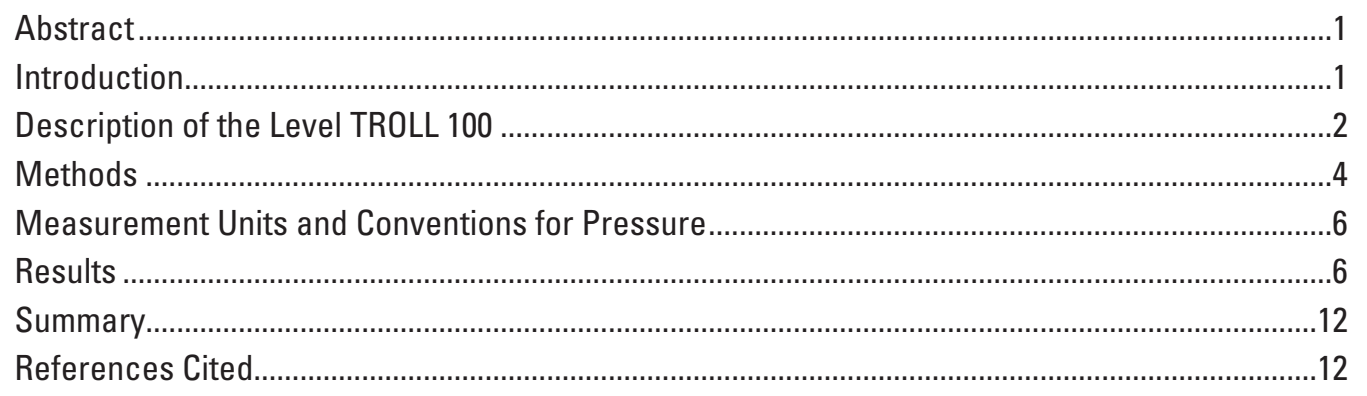




\section{Figures}

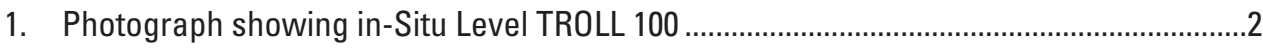

2. Graph showing pressures and soak temperatures applied during pressure cycling testing for three Level TROLL 100 instruments manufactured by In-Situ Inc

3. Graph showing temperatures and pressure applied during temperature cycling testing for three Level TROLL 100 instruments manufactured by In-Situ Inc.

4. Graph showing differences in pressures measured by the In-Situ Inc. Level TROLL 100 (serial number 129297) for nine standard pressures.

5. Graph showing differences in pressures measured by the In-Situ Inc. Level TROLL 100 (serial number 129597) for nine standard pressures.

6. Graph showing differences in pressures measured by the In-Situ Inc. Level TROLL 100 (serial number 129658) for nine standard pressures.

7. Graph showing difference in pressure measured by the In-Situ Inc. Level TROLL 100 (serial number 129297) for a standard pressure (2.666 pounds per square inch) over a temperature range of -20 to 50 degrees Celsius.

8. Graph showing difference in pressure measured by the In-Situ Inc. Level TROLL 100 (serial number 129597) for a standard pressure (2.666 pounds per square inch) over a temperature range of -20 to 50 degrees Celsius.

9. Graph showing difference in pressure measured by the In-Situ Inc. Level TROLL 100 (serial number 129658) for a standard pressure (2.666 pounds per square inch) over a temperature range of -20 to 50 degrees Celsius. 


\section{Tables}

1. Manufacturer's specifications for the In-Situ Inc. Level TROLL 100 absolute pressure sensing device....

2. Statistics for pressure differences for a pressure cycling test of three In-Situ Inc. Level TROLL 100 absolute pressure sensing devices for compensated temperatures of $0,20,40$, and $50^{\circ} \mathrm{C}$

3. Statistics for pressure differences for a temperature cycling test of three In-Situ Inc. Level TROLL 100 absolute pressure sensing devices for compensated temperatures of $0,20,40$, and $50^{\circ} \mathrm{C}$.

\section{Conversion Factors}

Inch/Pound to SI

\begin{tabular}{lcl}
\hline \multicolumn{1}{c}{ Multiply } & By & \multicolumn{1}{c}{ To obtain } \\
\hline & Length & \\
\hline inch (in.) & 2.54 & centimeter (cm) \\
inch (in.) & 25.4 & millimeter (mm) \\
foot (ft) & 0.3048 & meter (m) \\
\hline & Area & \\
\hline square inch $\left(\right.$ in $\left.^{2}\right)$ & 6.452 & square centimeter $\left(\mathrm{cm}^{2}\right)$ \\
\hline & Pressure & \\
\hline pound per square inch (psi) & 6.895 & kilopascal $(\mathrm{kPa})$ \\
\hline
\end{tabular}

In this report, pound per square inch is abbreviated as "psi" to match usage by the manufacturer.

Pressure in pound per square inch may be converted to feet of water $\left(\mathrm{ft}-\mathrm{H}_{2} \mathrm{O}\right)$ at standard gravity and water temperature of $10^{\circ} \mathrm{C}$ as follows: $\mathrm{ft}-\mathrm{H}_{2} \mathrm{O}=2.307 \mathrm{x} \mathrm{lb} / \mathrm{in}^{2}$

Temperature in degrees Celsius $\left({ }^{\circ} \mathrm{C}\right)$ may be converted to degrees Fahrenheit $\left({ }^{\circ} \mathrm{F}\right)$ as follows:

${ }^{\circ} \mathrm{F}=\left(1.8 x^{\circ} \mathrm{C}\right)+32$ 
This page intentionally blank 


\title{
Laboratory Evaluation of the Level TROLL 100 Manufactured by In-Situ Inc.-Results of Pressure and Temperature Tests
}

\author{
By Mark V. Carnley, Janice M. Fulford, and Myron H. Brooks
}

\begin{abstract}
The Level TROLL 100 manufactured by In-Situ Inc. was evaluated by the U.S. Geological Survey (USGS) Hydrologic Instrumentation Facility (HIF) for conformance to the manufacturer's accuracy specifications for measuring pressure throughout the device's operating temperature range. The Level TROLL 100 is a submersible, sealed, water-level sensing device with an operating pressure range equivalent to 0 to 30 feet of water over a temperature range of -20 to 50 degrees Celsius $\left({ }^{\circ} \mathrm{C}\right)$. The device met the manufacturer's stated accuracy specifications for pressure within its temperature-compensated operating range of 0 to $50^{\circ} \mathrm{C}$. The device's accuracy specifications did not meet established USGS requirements for primary water-stage sensors used in the operation of streamgages, but the Level TROLL 100 may be suitable for other hydrologic data-collection applications. As a note, the Level TROLL 100 is not designed to meet USGS accuracy requirements. Manufacturer accuracy specifications were evaluated, and the procedures followed and the results obtained are described in this report. USGS accuracy requirements are routinely examined and reported when instruments are evaluated at the HIF.
\end{abstract}

\section{Introduction}

The U.S. Geological Survey (USGS) Hydrologic Instrumentation Facility (HIF) evaluates the performance of instruments and equipment that are used to directly measure hydrologic data. These devices may measure properties needed to quantify streamflow (such as river stage, water velocity, or water discharge), to monitor groundwater levels, or to measure water-quality properties in a variety of field settings. In addition, the HIF evaluates the performance of instruments and equipment that are used in combination with devices that directly measure hydrologic data. These devices include data loggers and recorders, radios for data telemetry, power supplies, solar panels, batteries, cableway and bridge measuring equipment, and water-quality sampling devices. The performance of these devices is evaluated in a variety of ways; however, the primary factors evaluated are:

- the manufacturer's stated specifications for accuracy and resolution;

- any relevant USGS accuracy requirements;

- the ability of the device to operate under a wide range of environmental conditions at remote, unmanned field stations;

- power source and power consumption; and

- compatibility with existing USGS field hydrologic data-collection infrastructure and equipment.

The evaluations may involve extended operation in one or more field locations and (or) may employ testing chambers designed to reproduce a range of environmental conditions. Instrument and equipment evaluations are done primarily to determine if particular devices would be suitable for use by USGS personnel for hydrologic data collection.

This report describes the procedures followed and the results obtained from the pressure sensor evaluation testing of a commercially available, water-level measuring device, the Level TROLL 100. 


\section{Description of the Level TROLL 100}

The Level TROLL $100^{1}$ (fig. 1) includes a submersible pressure sensor, temperature sensor, data logger, and lithium battery mounted in a sealed, submersible, plastic housing. The battery has a 5-year life or 2 million readings capacity and is not user replaceable. Three Level TROLL 100s were tested: serial numbers 129297, 129597, and 129658. Selected manufacturer's specifications for this device are listed in table 1 and are available in the "In-Situ Level TROLL 100 Operator Guide" at http:// www.in-situ.com/products/Water-Level/Rugged-TROLL-Family/Rugged-TROLL-100-Instrument/resources (In-Situ.com, 2012). A special docking station is used to connect the device through the USB port of a computer. Proprietary software from the manufacturer is needed to communicate with the device using either a Windows personal computer or a Windows Mobile PDA (personal digital assistant).

The pressure sensor in the device is an absolute (non-vented), ceramic piezoresistive pressure sensor. Because the pressure sensor is absolute, it measures the sum of the local atmospheric pressure and the pressure exerted upon the sensor by an overlying column of water. When the local atmospheric pressure is measured independently, that measurement can be subtracted from the pressure measured by the device, and the resulting pressure value is a measure of the pressure exerted by a column of water above the device. This pressure, measured in pounds per square inch (psi), can be converted into feet of water $\left(\mathrm{ft}-\mathrm{H}_{2} \mathrm{O}\right.$ ) and can be used to continuously measure water level in a stream or well. For a detailed explanation of types of pressure measurements and sensors, see Freeman and others (2004). The device that was tested had a manufacturer's stated operating range of 0 to $30 \mathrm{ft}-\mathrm{H}_{2} \mathrm{O}$; this translates into a pressure range above atmospheric pressure (standard atmospheric pressure is $14.7 \mathrm{psi}$ ) of approximately 0 to 13 psi.

\footnotetext{
${ }^{1}$ Manufactured by In-Situ Inc., Ft. Collins, Colorado. At the time of testing, this unit was called the Level TROLL 100; In-Situ now calls the unit the Rugged TROLL 100 Instrument.
}

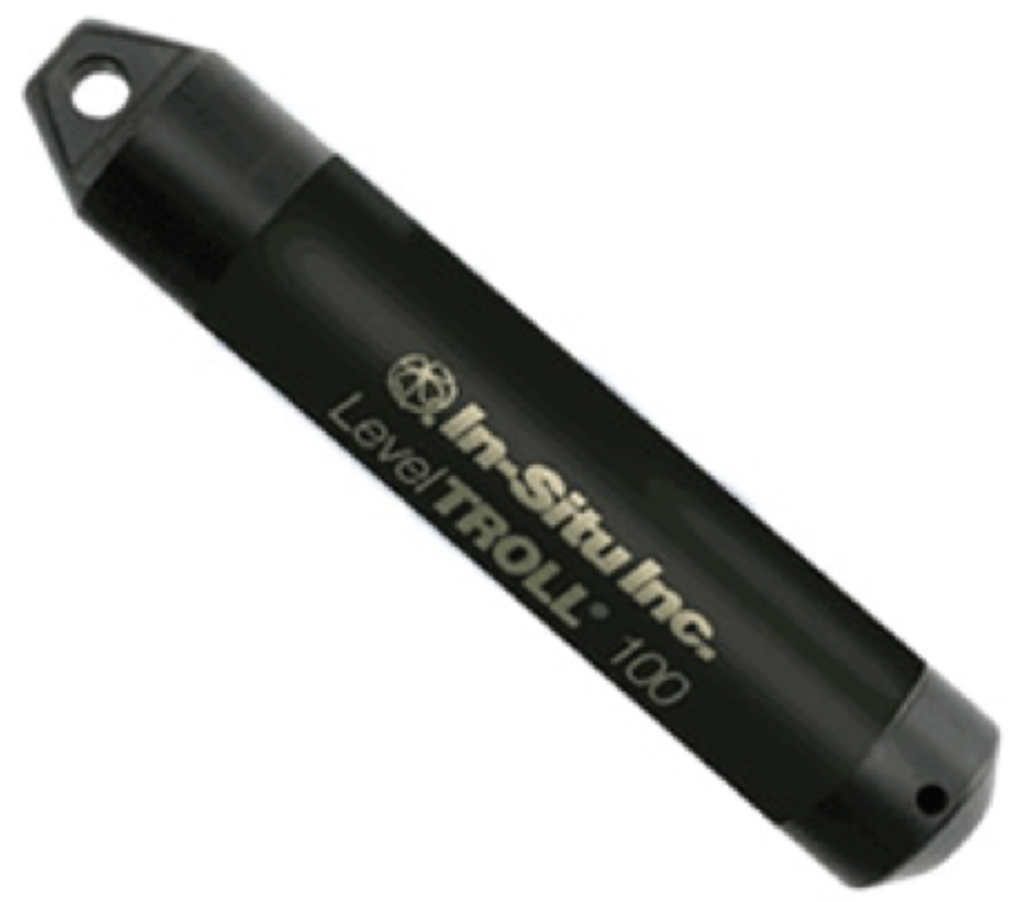

Figure 1. In-Situ Level TROLL 100 (photograph courtesy of In-Situ Inc). 
Table 1. Manufacturer's specifications for the In-Situ Inc. Level TROLL 100 absolute pressure sensing device.

$\left[ \pm\right.$, plus or minus; \%, percent; $\mathrm{ft}-\mathrm{H}_{2} \mathrm{O}$, feet of water; ${ }^{\circ} \mathrm{C}$, degrees Celsius $]$

\begin{tabular}{|c|c|}
\hline Housing dimensions & 1.03 inches in diameter x 5.5 inches in length \\
\hline Housing material & Polyoxymethylene (acetal) plastic \\
\hline Pressure sensor reading & Absolute \\
\hline Pressure sensor type & Piezoresistive, ceramic \\
\hline Pressure units & $\begin{array}{l}\text { Pounds per square inch absolute, kilopascals, inches of mercury, bar, millibar, millimeters } \\
\text { of mercury }\end{array}$ \\
\hline \multirow{3}{*}{ Pressure sensor accuracy } & Typical $\pm 0.1 \%$ full scale \\
\hline & \\
\hline & Maximum $\pm 0.3 \%$ full scale \\
\hline Pressure sensor range & 0 to $30 \mathrm{ft}-\mathrm{H}_{2} \mathrm{O}$ \\
\hline Burst pressure & $60 \mathrm{ft}-\mathrm{H}_{2} \mathrm{O}$ \\
\hline Pressure, compensated temperature range & 0 to $50{ }^{\circ} \mathrm{C}$ \\
\hline
\end{tabular}




\section{Methods}

Three Level TROLL 100 pressure-sensing devices were evaluated by subjecting them to varying pressures and temperatures in an environmental test chamber (ESPEC ${ }^{2}$ ESX-4CA, serial no. 015515). The environmental test chamber is capable of achieving and accurately maintaining temperatures from -20 to $50^{\circ} \mathrm{C}$ and is capable of achieving $\pm 1.0^{\circ} \mathrm{C}$ accuracy. The temperature chamber is biennially calibrated and verified using National Institute of Standards and Technology (NIST) traceable standards. The devices were installed inside the environmental test chamber and connected with pressure fittings and tubing through a chamber port to a test manifold located outside the test chamber. The test manifold was connected to a pressure controller (Ruska ${ }^{3}$ Model 7250xi, serial no. 64626) that used nitrogen gas to vary the pressure experienced by the devices. A Paroscientific ${ }^{4}$ Model PS-2 (serial no. 54278) gage pressure sensor was also inserted inside the test chamber and connected to the test manifold. The pressure sensor was used to monitor the pressure fittings and tubing for gas leaks that would compromise the integrity of the test. The pressure controller measured gage pressure. It is capable of achieving 0.003 percent accuracy and is annually calibrated and verified using NIST-traceable standards. Operation of the environmental chamber and pressure controller and data collection from the chamber sensors and the devices under test were automated with custom software (LabVIEW ${ }^{5}$ ). Two basic evaluations were performed. In the first, referred to as pressure cycling, the devices were subjected to pressures above ambient atmospheric pressure ranging from 0 to $13 \mathrm{psi}$ at temperatures ranging from -20 to $50^{\circ} \mathrm{C}$ (fig. 2). This test was performed primarily to evaluate the accuracy of the devices at multiple points over their operating temperature range when the pressure is changing relatively rapidly. During the pressure cycling evaluation the devices were equilibrated to, and held at, a constant temperature; the pressure was varied in a stepwise fashion from 0 to 13 and back to 0 psi. The order in which the pressures were applied was $0,1,2,3,4$, $7,9,11,13,11,9,7,4,3,2,1$, and 0 psi. The entire pressure cycle was completed in about 42 minutes. When a pressure cycle was completed, the environmental chamber temperature was changed to a new value. The transition between two temperature settings was accomplished in about 6 hours and 30 minutes. The next pressure cycle was initiated approximately 1 hour after the new temperature was achieved in order to allow the devices to equilibrate to the new temperature, a time period commonly referred to as "soak time." Atmospheric pressure readings used to adjust pressure cycling measurements were collected by an NIST-traceable Setra ${ }^{6}$ model 370 Digital Pressure Gage (serial no. 335314) capable of achieving 0.020 percent $( \pm 0.003$ psi) accuracy.

In the second test, referred to as temperature cycling, the devices were subjected to a series of temperatures at a constant pressure of $2.270 \mathrm{psi}$ above ambient atmospheric pressure (fig. 3). This evaluation was designed to examine the stability and accuracy of the devices during substantial temperature variations across their entire operating temperature range. The temperatures experienced by the devices varied continuously between -20 and $50^{\circ} \mathrm{C}$, and three complete temperature cycles were completed over a 150-hour time period. Atmospheric pressure readings used to adjust pressure during the temperature cycling measurements were collected by the barometric sensor in the Ruska pressure controller, capable of achieving 0.014 percent $( \pm 0.002 \mathrm{psi})$ accuracy.

\footnotetext{
${ }^{2}$ ESPEC North America, Inc.

${ }^{3}$ Ruska Instrument Corp.

${ }^{4}$ Paroscientific, Inc.

${ }^{5}$ System design software by National Instruments Corp.

${ }^{6}$ Setra Sensing Solutions.
} 


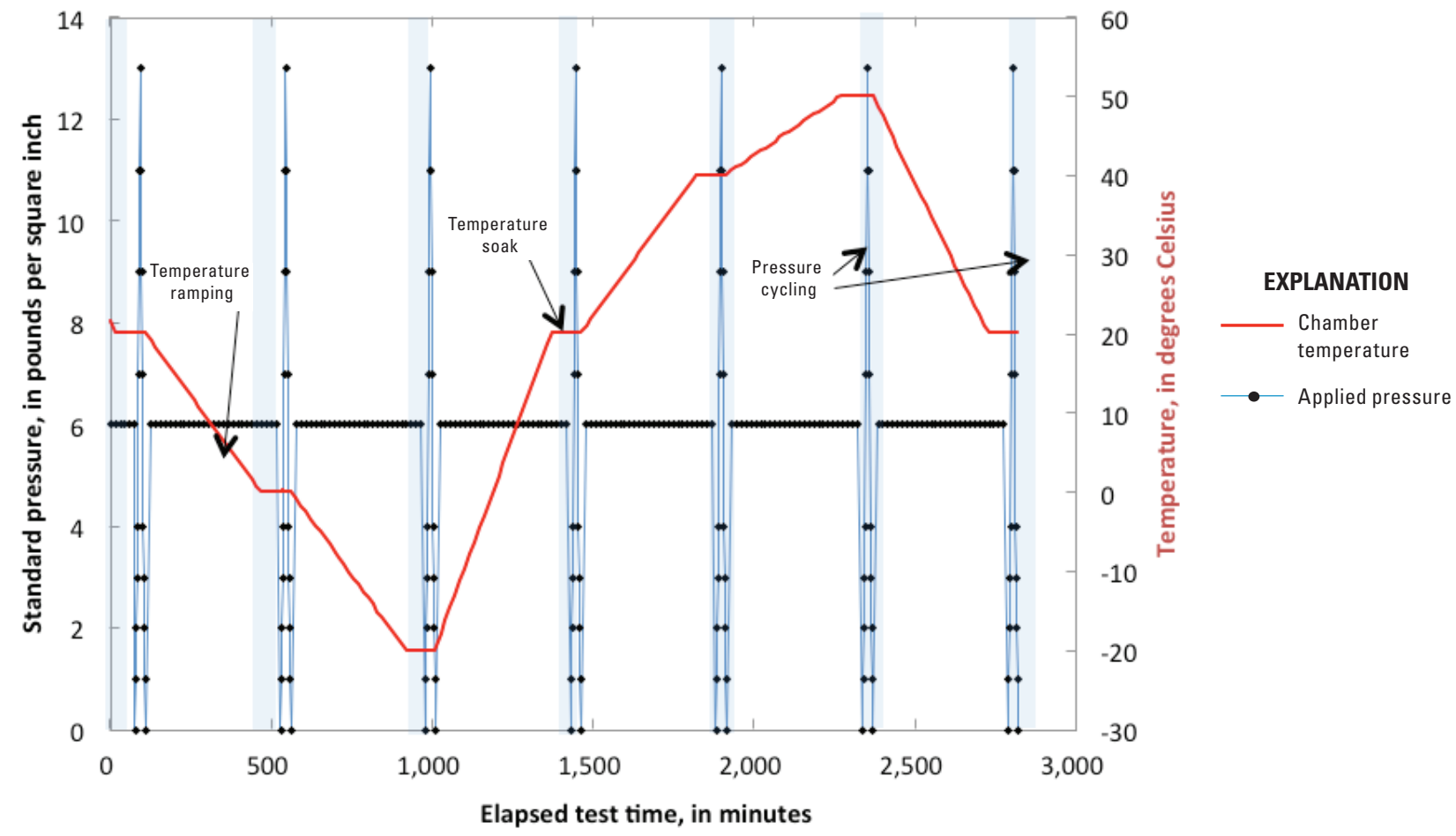

Figure 2. Pressures and soak temperatures applied during pressure cycling testing for three Level TROLL 100 instruments manufactured by In-Situ Inc.

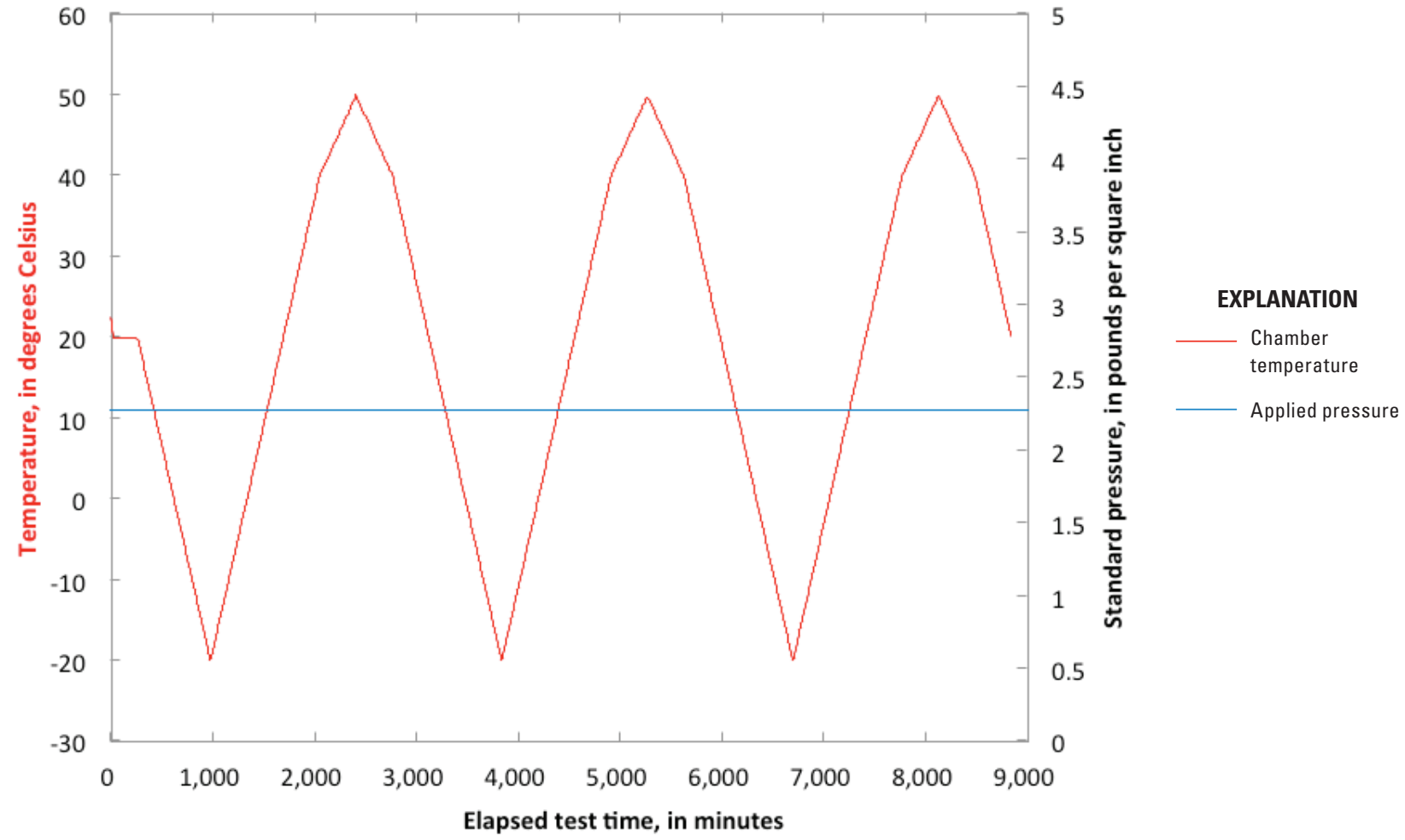

Figure 3. Temperatures and pressure applied during temperature cycling testing for three Level TROLL 100 instruments manufactured by In-Situ Inc. 


\section{Measurement Units and Conventions for Pressure}

In this report, absolute, gage, and standard pressure terms are presented. Pressure sensors can have the sensing element either vented or sealed to the atmosphere. The pressure sensing devices that were evaluated were sealed to the atmosphere; they measure pressure in pounds per square inch, including atmospheric pressure (psia). The barometric sensor used to measure atmospheric pressure also was sealed and measured pressure in psia. The pressure controller sensor used to vary and measure pressures was a vented sensor and measured what is termed standard pressure in this report, in pounds per square inch excluding atmospheric pressure (psig).

Data collected by the barometric sensors were used to correct the difference between the pressure sensing devices and the pressure controller for the effect of atmospheric pressure. In the laboratory evaluation and as reported here, differences between the pressures measured by a device and standard pressures were corrected for barometric pressure and were computed as:

$$
\mathrm{P}_{\text {device }}-\mathrm{P}_{\text {controller }}-\mathrm{P}_{\text {barometer }}=(\mathrm{psia}) \text {, }
$$

where

$\begin{array}{ll}\mathrm{P}_{\text {device }} & \text { is the absolute pressure measured by the pressure sensing device, } \\ \mathrm{P}_{\text {controller }} & \text { is the gage pressure measured by the Ruska pressure controller, and } \\ \mathrm{P}_{\text {barometer }} & \text { is the atmospheric pressure measured by a barometer. }\end{array}$

Throughout this report, pressure differences between the device and standard pressure refer to values computed using this equation. In order to minimize confusion, all pressure differences are simply reported in psi even though the actual data being compared were measured in psia and the known pressures were being measured in both psia (the barometer) and psig (the pressure controller).

\section{Results}

The performance of the three devices at varying temperatures and pressures was evaluated using the methods described above. For the pressure cycling evaluation, the difference between the pressure measured by the device and the standard pressure adjusted for atmospheric pressures versus the standard pressure is shown for each of the three devices in figures 4 through 6. Symbols are used to denote the five temperatures $\left(-20,0,20,40\right.$, and $\left.50{ }^{\circ} \mathrm{C}\right)$ at which pressures measured by the devices were recorded. Horizontal dotted lines in the figures denote two manufacturer-supplied accuracy ranges: "Maximum" $( \pm 0.3 \%$ of full scale) and "Typical" $( \pm 0.1 \%$ of full scale).

The three devices performed similarly and exhibited a small but reasonably consistent positive bias for all pressure measurements made at temperatures ranging from -20 to $50{ }^{\circ} \mathrm{C}$. All pressure measurements made at $-20^{\circ} \mathrm{C}$ resulted in differences from the known pressure that exceeded the device's stated accuracy specification (figs. 4, 5, and 6). This result is not surprising because $-20{ }^{\circ} \mathrm{C}$ is outside of the temperature-compensated range for the pressure sensor.

Summary statistics for the pressure differences measured during the pressure cycling test over the compensated temperature range are provided in table 2. Mean pressure differences estimated the device measurement bias (systematic uncertainty), and standard deviations of the pressure differences estimated the device measurement variability (random uncertainty). For all three devices, the mean pressure differences varied from 0.01 to $0.026 \mathrm{psi}$ and were within the manufacturer's accuracy specification for pressure measurements made at temperatures within the temperature-compensated range. The difference between the pressure measured by the device and the standard pressure was within the manufacturer's stated accuracy specification of $\pm 0.039 \mathrm{psi}$ except for four measurements that were $+0.040 \mathrm{psi}$. The standard deviations of the pressure differences were small and varied from 0.006 to $0.008 \mathrm{psi}$. All three devices had low measurement variability. The difference in the device pressure reading at the same temperature and pressure made at the start and the end of the test (drift) was small, between -0.003 and 0.002 psi. 


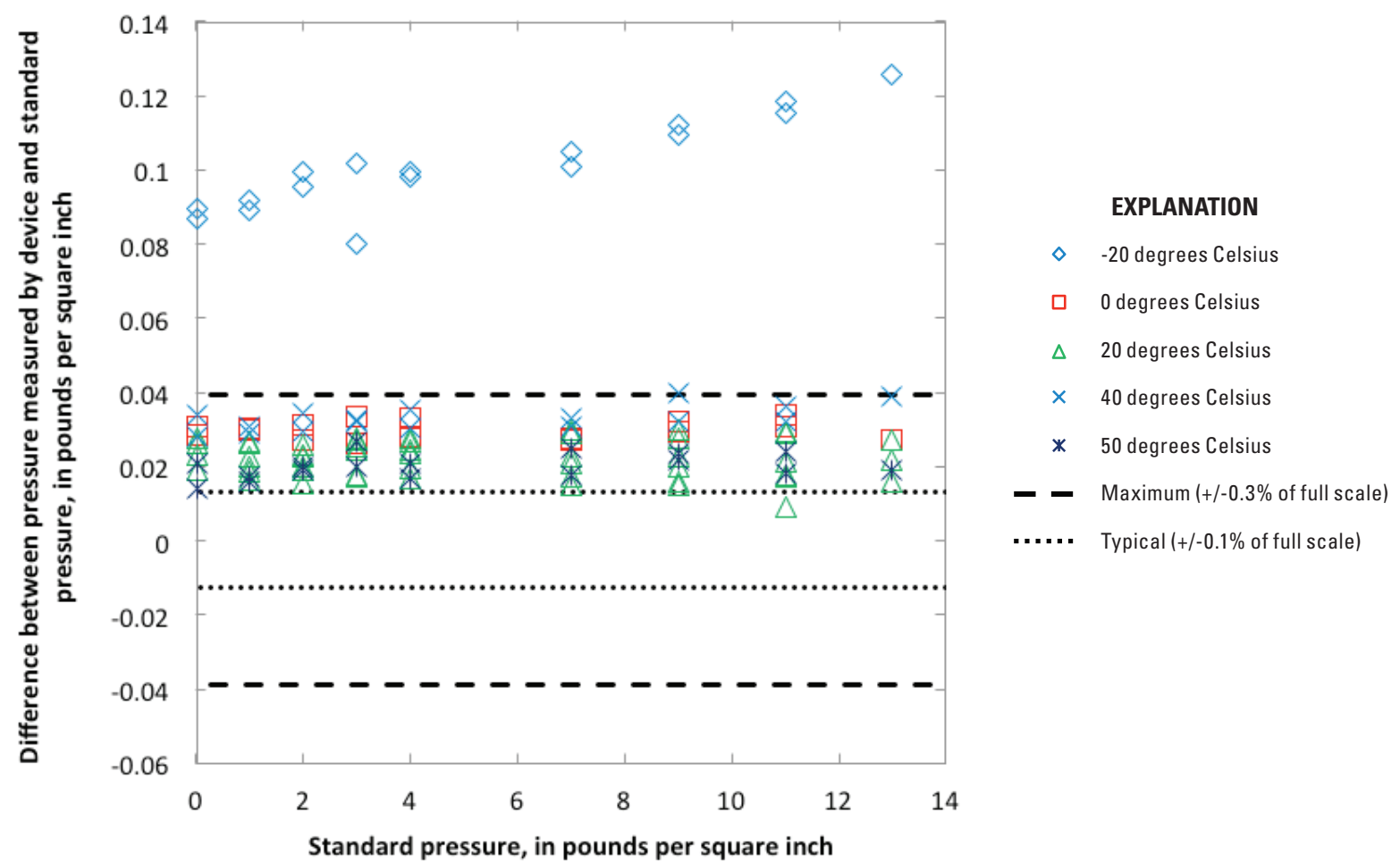

Figure 4. Differences in pressures measured by the In-Situ Inc. Level TROLL 100 (serial number 129297) for nine standard pressures.

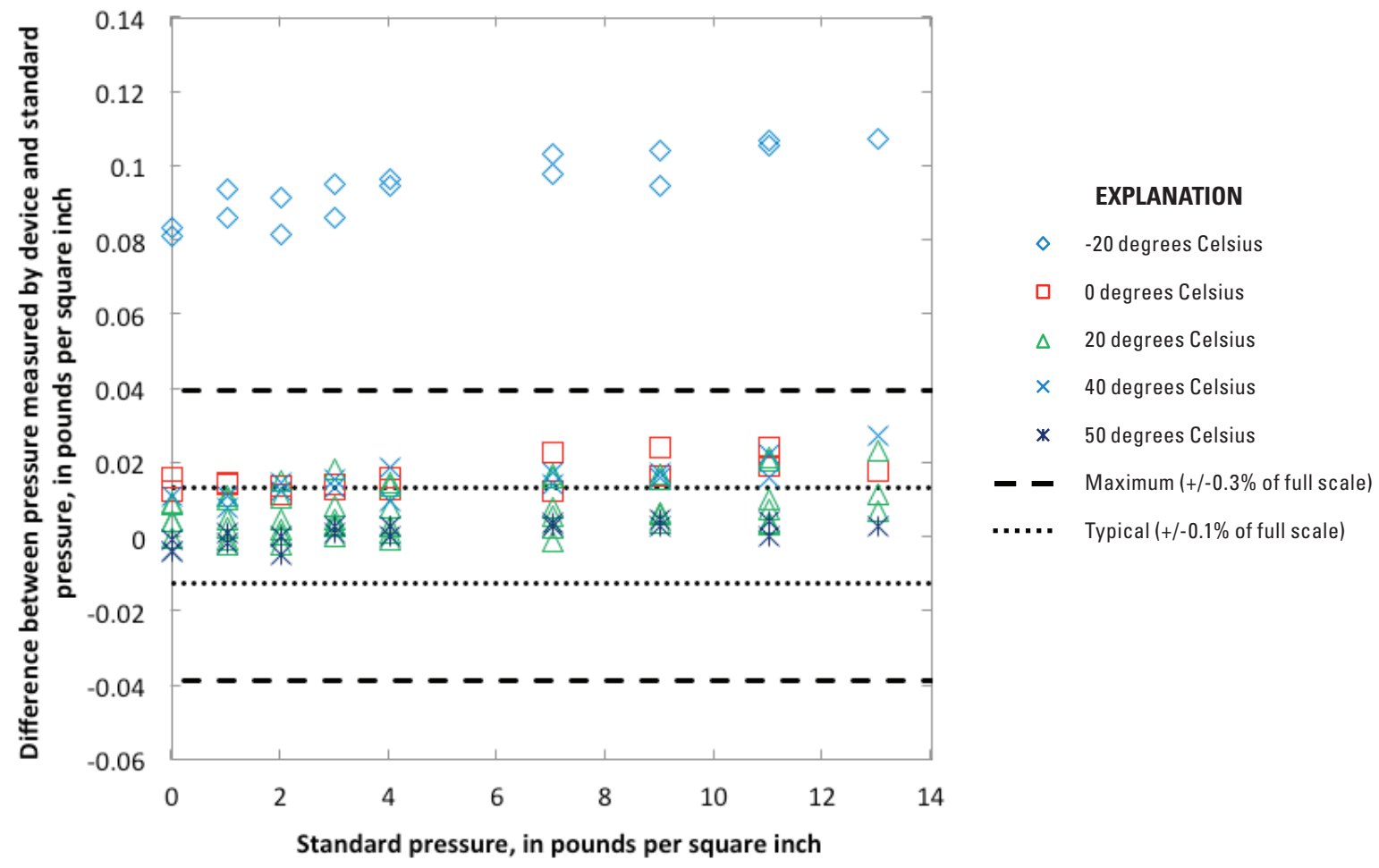

Figure 5. Differences in pressures measured by the In-Situ Inc. Level TROLL 100 (serial number 129597) for nine standard pressures. 


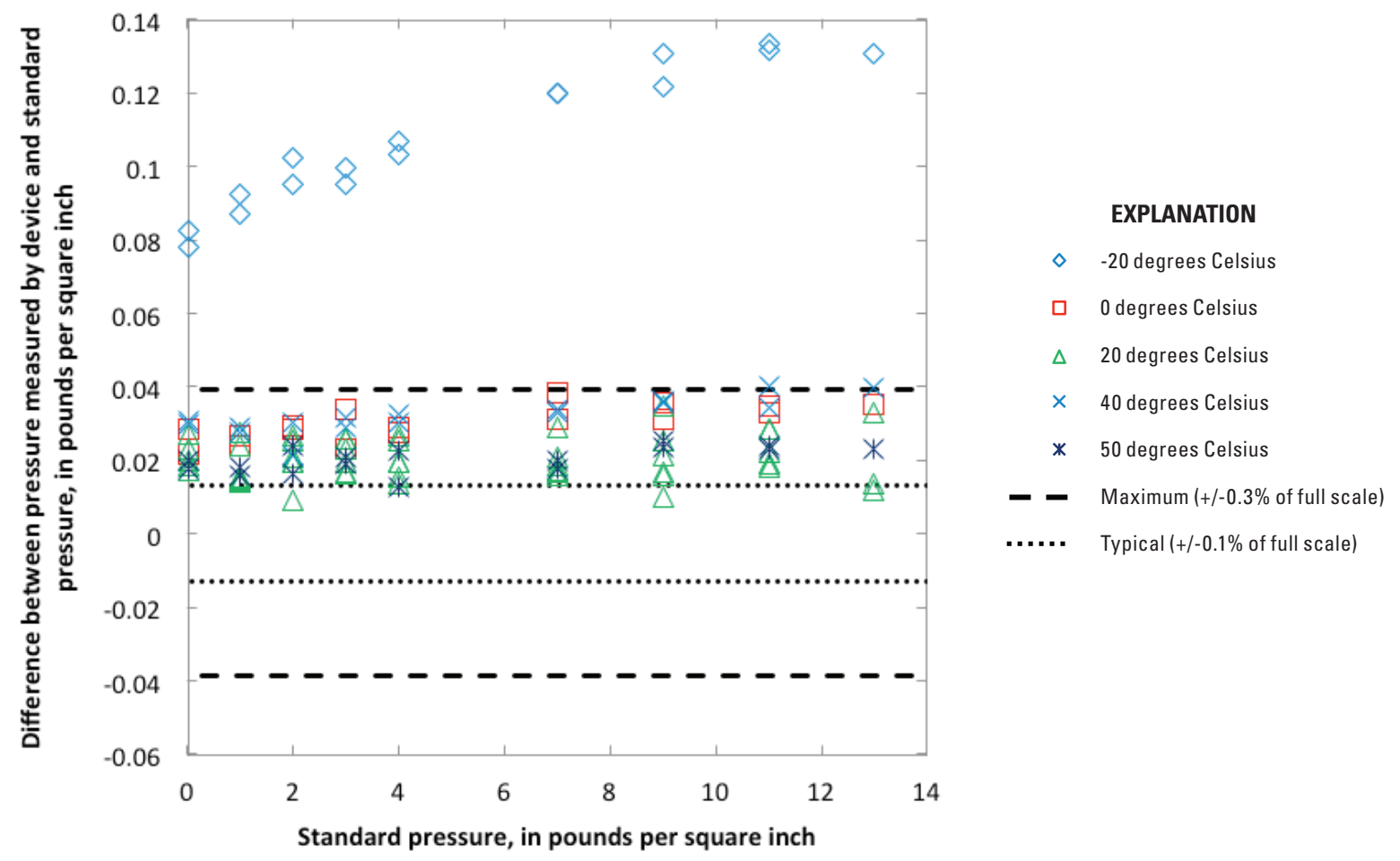

Figure 6. Differences in pressures measured by the In-Situ Inc. Level TROLL 100 (serial number 129658) for nine standard pressures.

Table 2. Statistics for pressure differences for a pressure cycling test of three In-Situ Inc. Level TROLL 100 absolute pressure sensing devices for compensated temperatures of $0,20,40$, and $50^{\circ} \mathrm{C}$.

[psi; pounds per square inch]

\begin{tabular}{|c|c|c|c|c|}
\hline Statistic & \multicolumn{3}{|c|}{ Serial number of tested device } & $\begin{array}{c}\text { All } \\
\text { devices }\end{array}$ \\
\hline Maximum (psi) & 0.04 & 0.027 & 0.04 & 0.02 \\
\hline Mean (psi) & 0.026 & 0.01 & 0.025 & 0.02 \\
\hline Standard deviation (psi) & 0.006 & 0.008 & 0.007 & 0.007 \\
\hline Drift (psi) & -0.003 & 0.002 & -0.003 & \\
\hline
\end{tabular}


The average measurement uncertainty for the three devices for the pressure cycling test, $U_{p}$, was computed using a simplified uncertainty analysis based on International Organization for Standardization (ISO) methods (International Organization for Standardization, 2008). Systematic (mean differences) and the random (standard deviation of the differences) uncertainties (or errors) were grouped into a combined uncertainty using the following equation:

$$
U_{p}=\left[\left(\frac{\Sigma x_{p}}{3}\right)^{2}+\left(\frac{\Sigma s_{p}}{3}\right)^{2}\right]^{1 / 2},
$$

where

$x_{p} \quad$ is the mean pressure difference for the $p$ th device and

$s_{p}^{p} \quad$ is the standard deviation of the pressure differences for the $p$ th device. The result was a combined value of uncertainty of $\pm 0.041 \mathrm{psi}$ for the three devices.

Results obtained from the temperature cycling evaluation of the three devices are displayed in figures 7-9. The calculated difference between the pressure measured by the device and the standard pressure adjusted for atmospheric pressure (known pressures) are plotted in each figure as a function of chamber temperature. Pressure differences that were measured outside of the temperature-compensated range are noted in the figures. Horizontal dotted lines in the figures denote two manufacturersupplied accuracy ranges: "Maximum" ( $\pm 0.3 \%$ of full scale) and "Typical" ( $\pm 0.1 \%$ of full scale).

As was the case with the pressure cycling evaluation, the differences between pressures measured by the devices and the standard pressures adjusted for atmospheric pressure were within the manufacturer's stated accuracy limits for all measurements made within the temperature-compensated range. When the sensors were subjected to temperatures below $0{ }^{\circ} \mathrm{C}$, the pressure differences increased with increasingly colder temperatures and eventually exceeded the manufacturer's stated accuracy limits. The "looping" of the data in figures 7, 8, and 9 is an indication of the devices' temperature hysteresis. All devices had temperature hysteresis and measured slightly higher pressure differences for rising temperatures and slightly lower pressure differences for falling temperatures (figs. 7-9).

Summary statistics for the pressure differences measured during the temperature cycling test for the compensated temperature range are provided in table 3. Mean pressure differences and standard deviations of the pressure differences are used to estimate the device measurement bias and the device measurement variability, respectively, for a constant pressure over the compensated temperature range of the device. Measured pressure differences ranged from 0.036 to -0.013 psi for the three devices. All three devices had a small positive bias that was within the manufacturer's stated accuracy limits. The mean pressure differences were from 0.003 to $0.017 \mathrm{psi}$. The standard deviations of the pressure differences for the three devices were small and varied from 0.007 to 0.008 psi. All three devices exhibited low measurement variability for the temperature cycling test. The difference in the device pressure reading at the same temperature and pressure made at the start and the end (drift) of the test for all three devices was small, between -0.001 and 0.005 psi.

The average measurement uncertainty of the three devices for the temperature cycling test, $U_{t}$, was computed using a simplified uncertainty analysis based on ISO methods (International Organization for Standardization, 2008) and the following equation:

$$
U_{t}=\left[\left(\frac{\Sigma x_{t}}{3}\right)^{2}+\left(\frac{\Sigma s_{t}}{3}\right)^{2}\right]^{1 / 2},
$$

where

$x_{t} \quad$ is the mean pressure difference for the $t$ th device and

$s_{t} \quad$ is the standard deviation of the pressure differences for the $t$ th device. The result was a combined value of uncertainty of $\pm 0.014 \mathrm{psi}$ for the three devices.

The positive bias observed during the evaluations was within the manufacturer's stated accuracy limits over the temperature-compensated range $\left(0\right.$ to $\left.50^{\circ} \mathrm{C}\right)$. Temperatures in the operating range and not in the compensated range were, not surprisingly, outside of the manufacturer's accuracy limits. It is important to note that the devices evaluated are intended to measure pressures while submerged in liquid water. It is possible that they could encounter the types of low temperatures $\left(-10^{\circ} \mathrm{C}\right.$ and lower) that caused their measurement accuracy to drift outside of the manufacturer's specifications when deployed in a field setting. However, if those temperatures were experienced, the sensors could not possibly provide meaningful water-level data at that point, as all of the water in the vicinity of the device would be in the form of ice. USGS accuracy specifications for stage measurement at gaging stations are described in Office of Surface Water Technical Memorandum No. 96.05 (U.S. Geological 


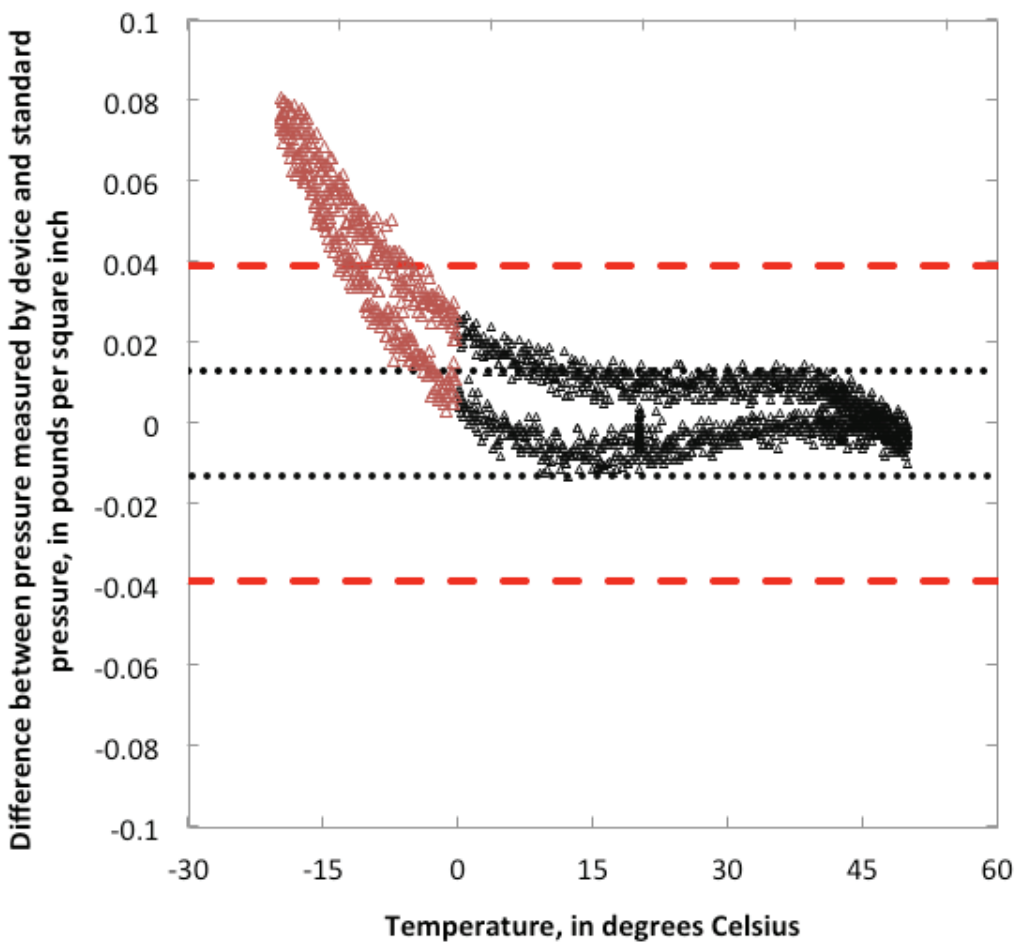

\section{EXPLANATION}

$\Delta \quad$ Compensated range

$\Delta \quad$ Out of compensated range

- Maximum $(+/-0.3 \%$ of full scale)

Typical $(+/-0.1 \%$ of full scale)

Figure 7. Difference in pressure measured by the In-Situ Inc. Level TROLL 100 (serial number 129297) for a standard pressure (2.666 pounds per square inch) over a temperature range of -20 to 50 degrees Celsius.

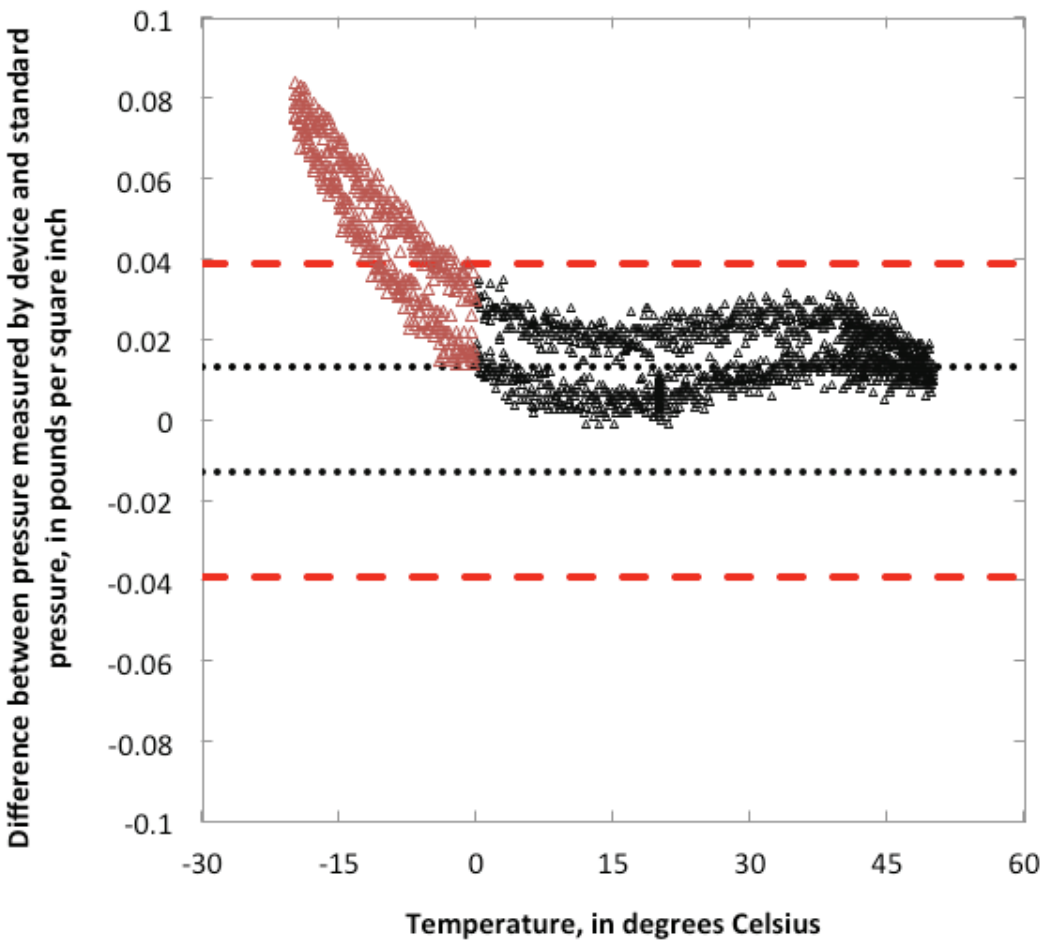

EXPLANATION

$\Delta \quad$ Compensated range

$\Delta \quad$ Out of compensated range

- Maximum $(+/-0.3 \%$ of full scale)

...... Typical $(+/-0.1 \%$ of full scale $)$

Figure 8. Difference in pressure measured by the In-Situ Inc. Level TROLL 100 (serial number 129597) for a standard pressure (2.666 pounds per square inch) over a temperature range of -20 to 50 degrees Celsius. 


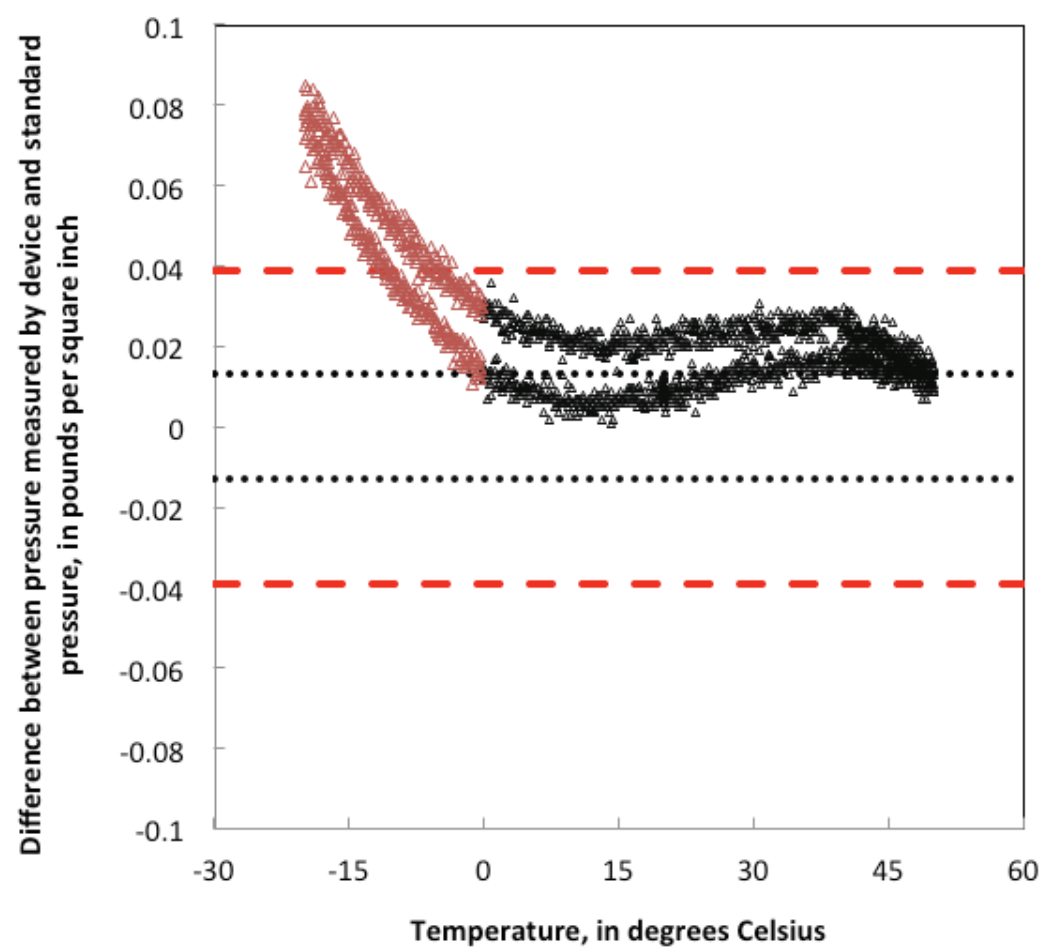

EXPLANATION

$\Delta \quad$ Compensated range

$\Delta \quad$ Out of compensated range

- Maximum $(+/-0.3 \%$ of full scale)

...... Typical $(+/-0.1 \%$ of full scale)

Figure 9. Difference in pressure measured by the In-Situ Inc. Level TROLL 100 (serial number 129658) for a standard pressure (2.666 pounds per square inch) over a temperature range of -20 to 50 degrees Celsius.

Table 3. Statistics for pressure differences for a temperature cycling test of three In-Situ Inc. Level TROLL 100 absolute pressure sensing devices for compensated temperatures of $0,20,40$, and $50^{\circ} \mathrm{C}$.

[psi; pounds per square inch]

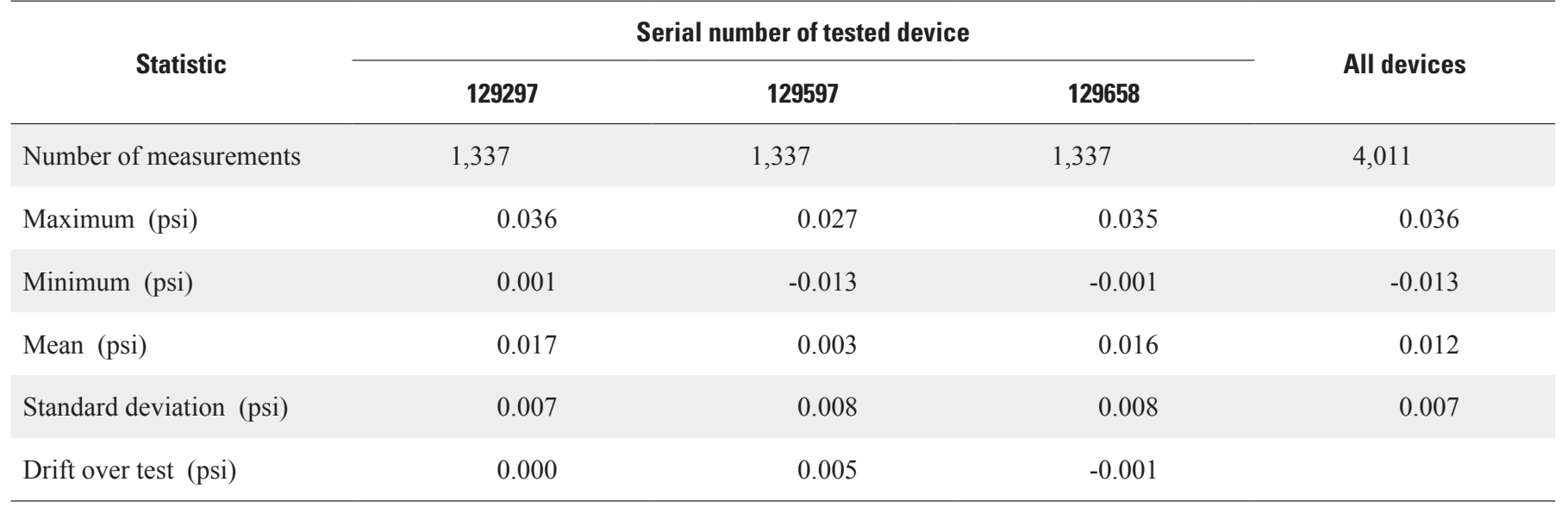


Survey, 1996). The specifications state that the accuracy requirement for "non-submersible pressure sensor-instruments" is "the larger of $0.01 \mathrm{ft}$ or 0.10 percent of reading." This specification was established before the widespread use of submersible pressure sensors by the USGS; it has been applied to submersible sensors as they have increased in availability and usage through time. Using a conversion of $2.307 \mathrm{ft}-\mathrm{H}_{2} \mathrm{O}$ per $1 \mathrm{psi}$, it can be easily determined that the sensors evaluated in this study did not meet the USGS accuracy specification for stage measurement. For example, using the data presented in figure 4, most of the measurements of pressure that were made at temperatures of $0,20,40$, and $50^{\circ} \mathrm{C}$, and at pressures that were equal to or less than $4 \mathrm{psi}$, differed from the standard value by $0.02 \mathrm{psi}$ or more. Pressure differences equaling or exceeding 0.02 psi correspond to water-level differences of $0.05 \mathrm{ft}-\mathrm{H}_{2} \mathrm{O}$ or more. Standard pressures ranging from 0 to 4 psi are all equivalent to a water level less than $10 \mathrm{ft}-\mathrm{H}_{2} \mathrm{O}$, and the USGS accuracy specification for all such water levels is no more than $0.01 \mathrm{ft}-\mathrm{H}_{2} \mathrm{O}$. A similar analysis of data for the sensors presented in figures 4 through 9 yields the same results at numerous temperatures and standard pressures.

\section{Summary}

Three In-Situ Inc. Level TROLL 100 submersible, sealed, water-level sensing devices with an operating pressure range equivalent to 0 to 30 feet of water were evaluated to determine if they met the manufacturer's stated accuracy specifications and if they were suitable for use in U.S. Geological Survey (USGS) hydrologic data-collection activities. The evaluations involved subjecting the devices to a range of pressures from 0 to 13 pounds per square inch (psi) above atmospheric pressure and a range of temperatures from -20 to $50^{\circ} \mathrm{C}$. The three devices met the manufacturer's stated accuracy specifications within the temperature-compensated operating range of 0 to $50^{\circ} \mathrm{C}$. The devices evaluated did not meet USGS specifications for accuracy of stage measurements at USGS continuous record streamflow-gaging stations. Office of Surface Water Technical Memorandum No. 96.05 (U. S. Geological Survey, 1996) states that the accuracy needed to support computation of discharge from a stagedischarge relation and the procedures and equipment used are to be capable of sensing and recording stage with an uncertainly of no more than 0.01 foot or 0.20 percent of indicated reading, whichever is larger.

The estimated combined measurement uncertainty for the pressure cycling test was $\pm 0.041 \mathrm{psi}$ and for the temperature cycling test was \pm 0.014 psi for the three devices. The accuracy specifications for the devices did not meet established USGS requirements for primary water-stage sensors used in the operation of streamflow gaging stations, but the Level TROLL 100 may be suitable for other hydrologic data-collection applications.

\section{References Cited}

Freeman, L.A., Carpenter, M.C., Rosenberry, D.O., Rousseau, J.P., Unger, Randy, and McLean, J.S., 2004, Use of submersible pressure transducers in water-resources investigations: U.S. Geological Survey Techniques of Water-Resources Investigations, book 8, chap. A3, p. 2-4, http://pubs.usgs.gov/twri/twri8a3/.

In-Situ.com, 2012, Rugged TROLL 100 and 200 operator's manual, accessed March 26, 2013, from http://www.in-situ.com/ products/Water-Level/Rugged-TROLL-Family/Rugged-TROLL-100-Instrument/resources.

International Organization for Standardization, 2008, Motivation and basis for Recommendation INC-1 (1980), Annex E in Uncertainty of measurement-Part 3, Guide to the expression of uncertainty in measurement (GUM:1995): Geneva, Switzerland, International Organization for Standardization, ISO/IEC Guide 98-3:2008(E), p. 6.

U.S. Geological Survey, 1996, Policy concerning accuracy of stage data: U.S. Geological Survey Office of Surface Water Technical Memorandum 96.05, accessed April 5, 2013, at http://water.usgs.gov/admin/memo/SW/sw96.05.html. 
This page intentionally blank 
